\title{
Integration of Information Technology in the Public Music Curriculum of Secondary Vocational Schools under the Background of Information 2.0
}

\author{
Yang Yi \\ Guangdong Finance and Economics Vocational and Technical School, Nanhai District, Foshan, \\ Guangdong, China
}

Keywords: Information Technology, Music curriculum, Informatization

\begin{abstract}
With the continuous development of information technology, the development and reform of education informatization are imminent. Exploring the application of public music teaching methods in secondary vocational schools under the new model will play a specific role in improving teaching efficiency, improving students' music literacy, and improving teachers' information technology capabilities. Therefore, this article uses the secondary vocational public music course to explore the integration and feasibility of information technology in teaching.
\end{abstract}

\section{Research background}

In the era of informatization for all, the relevant national education administrative departments have successively issued the "Education Informatization Ten-Year Development Plan (20112020)", the "Education Informatization 2.0 Action Plan", and the "Information Technology Ability Improvement Project for Primary and Secondary School Teachers" in recent years. 2.0" and other documents, local education administrative departments have also successively launched various teacher informatization engineering training and teaching informatization competitions. In actual secondary vocational Teaching, information technology has become one of the required teaching methods. Because secondary vocational students are in adolescence, they are more interested in new things, games, etc., like interesting short videos, like hands-on operations, and like Teaching are gamified, so information technology can help teachers achieve exciting and efficient teaching effects a large extent.

\section{Problems in public music teaching in secondary vocational schools under the background of information 2.0}

\subsection{Some teachers are weak in information technology}

Through interviews and surveys, in the teaching of music teachers, informatization methods are mainly reflected in the use of multimedia (audio and video, PPT); online resources mainly come from platforms such as Baidu, Tencent Video, Youku Video, etc., and rarely come from specialized teaching resources Platforms, such as China University MOOC (MOC), AiCours Network, Smart 
Vocational Education, etc.; after-school homework guidance is still based on paper homework or on-site guidance, with very little use of information technology. Few people can master more than three kinds of micro-class production technologies, and even few can independently use and operate smart classrooms.

\subsection{Insufficient school software and hardware equipment}

As the saying goes, it is difficult for a clever woman to cook without rice. In addition to teachers' information technology ability, information teaching needs to rely on specific software and hardware equipment. In the relatively developed cities of the Pearl River Delta, the coverage rate of classroom information equipment in primary and secondary schools reaches $100 \%$, which is mainly reflected in essential equipment such as computers, speakers, amplifiers, teaching whiteboards, and projectors. These infrastructures allow teachers to get rid of the problems of slow writing on the blackboard and difficulty in visualizing teaching content in traditional teaching, which shows that information technology, has a positive impact on teaching effects to a certain extent. However, only these infrastructures are far from enough. More advanced information technology methods are needed to make classrooms efficient and fun, such as the construction of online teaching platforms, the construction of brilliant classrooms, and the construction of micro-course recording and broadcasting rooms. However, these hardware and software equipment require a particular capital investment. , So it has not been popularized in every school.

\subsection{Some teachers are not very aware of the construction of teaching informatization}

Some teachers do not have a strong awareness of the construction of educational informatization, mainly based on the following reasons:

\subsubsection{Some teachers lack the spirit of lifelong learning}

Information technology changes with each passing day, and teachers need to absorb and learn continuously. Informatization of teaching, from micro-classes, MOOCs, smart classrooms to live and online teaching, in just five or six years, various new forms have emerged one after another. The traditional teaching methods have their advantages, but if teachers are only If you stay on your own feet and do not want to try and learn more, you will never be able to keep up with the pace of changes in information technology. It will be challenging to improve your teaching ability continuously.

In actual teaching, it can be found that some teachers have a mentality of job burnout, thinking that traditional teaching methods can complete the teaching content, and are unwilling to spend time researching and learning new teaching methods and new information technologies. Teaching information technology does require teachers to spend time and energy to learn and master. Before being proficient in technology will bring certain pressure and risks to teachers' teaching to a certain extent, such as unskilled technology in the teaching process. Problems include a confusing teaching process, inaccurate control of teaching time, and inability to implement teaching links. Therefore, teachers must learn and master new information technology in constant trial and error, and teachers need to have the spirit of lifelong learning.

The learning characteristics of secondary vocational students are different from those of ordinary middle school students. Most of them like hands-on practice, active teaching, dislike boring theoretical knowledge, dislike the full class style, and public music, as a public introductory course, is a non-professional course, to a certain extent Not being valued by students, music teachers should 
master new teaching methods and understand new teaching concepts, and use information technology to make students move and make the classroom alive.

\subsubsection{Less information technology training for teachers}

The mastery of information technology for teachers cannot rely solely on the efforts of teachers. Educational administrative agencies, schools, and information technology industries should provide teachers with corresponding information technology skills training from multiple perspectives. Everyone can popularize information technology knowledge and skills. Teachers, such as educational administrative agencies, can encourage teachers to teach information technology through competition training; schools can cooperate with relevant information technology companies to carry out corresponding information technology equipment training and lectures to broaden teachers' horizons on teaching information technology. Let every teacher understand the latest development direction of teaching information technology, and enhance teachers' awareness of teaching information construction.

\section{The feasibility of the integration of information technology in the public music curriculum of secondary vocational schools}

\subsection{Improve teachers' information technology ability}

The relevant education administration agency of Guangdong Province will carry out the "Guangdong Province Primary and Secondary School Teachers' Information Technology Application Ability Enhancement Project 2.0" from 2020 to 2021. Until November 2021, there will be two sessions with a total of 15,015 participating schools. The chemical team has 11,882 teams, with a total of 675,272 trainees. Relevant pilot schools have carried out relevant training and research for all teachers in the school and divided the teachers' "Information Technology Ability Improvement Project 2.0" into five dimensions (academic analysis, teaching design, learning method guidance, academic evaluation, integration, and innovation) and 28 For application ability points, each teacher chooses no less than three ability points, which need to cover three dimensions. Participate in the corresponding online course learning and school-based practical application according to the ability points, and evaluate the improvement of the ability points. Teachers learn about the latest information technology teaching concepts and related skills through online courses early and practice them through school-based training in the later stage. School-based training is for teachers to implement the information technology concepts and skills and apply them to teaching. It includes several links: teaching seminars, lectures and evaluations, research assignments, and offline activities. Each teaching and research group will eventually form an information-based teaching topic. Through this series of learning and practice, the information technology ability of all teachers in the school can be effectively improved.

\subsection{The Application of Information Technology in the Public Music Courses of Secondary Vocational Schools--Taking the chapter of "Xiqu" as an example}

Opera is an extended module in the public music curriculum, and it is a restricted elective content that meets the needs of students' continuing learning and personality development. (The Ministry of Education issued the "Syllabus for Public Art Courses in Secondary Vocational Schools" in 2013)

As a traditional Chinese culture, Xiqu has penetrated various provinces and cities in China and can be seen everywhere in life. However, due to the complexity and uniqueness of its performance 
form, it is necessary to use information technology to visualize and concretize it to make it more It is easy for students to understand and love. The following will explore the application of information technology in the first lesson of Chinese opera from three links before class, during class, and after class.

\subsubsection{Before class}

Before class, teachers' preparation can be divided into three aspects: preparing teaching materials, preparing teaching methods, and preparing students. Prepare teaching materials, not just prepare the content in the textbook. Xiqu is a comprehensive art that integrates music, dance, performance, literature, and other arts. It is necessary to experience the beauty of Xiqu from the visual and audio aspects, so video materials are indispensable; Video materials are divided into two types, one is drama performance videos, which can be searched and downloaded through various video software; the other is a micro-class video of a certain knowledge point, which can be downloaded through the search and download of the teaching platform, or the teacher can record the micro-class. There are several ways to record micro-classes: PPT, H5, Katyusha, Stone, Love Editing, and other software or professional micro-class recording and broadcasting rooms can allow teachers to achieve different effects of micro-class recording. Preparatory teaching method, that is, choosing the appropriate teaching method, commonly used teaching methods include "online and offline mixed teaching," "action-oriented method," and so on. Prepare students to understand the academic situation, and information technology can help teachers analyze the characteristics of students and form data so that teachers can better adjust the content of the classroom. For example, "Questionnaire Star" conducts questionnaire surveys, and online teaching platforms conduct preclass tests.

\subsubsection{In class}

In the learning process, students' learning initiative positively impacts the learning effect. At the same time, the traditional classroom structure is teacher-centered, and students are primarily in passive and receptive learning. Through the integrated teaching of information technology, students' learning enthusiasm can be fully mobilized. The probability of students' hands-on operation can be increased, conducive to giving full play to students' creativity. The use of smart classrooms can form data of the teaching process and save classroom records, which is convenient for teachers to evaluate and reflect after class. In addition to teaching in this classroom, the smart classroom can also realize remote classroom teaching interaction and create a teaching atmosphere. Real-time connection, integration of teaching resources, optimization of teaching methods, breaking space constraints, such as remote connection with Xiqu school, so that students can feel the form and atmosphere of the training of Xiqu actors. In addition to regular courseware and blackboard writing, interactive whiteboards can better realize teacher-student interaction and activate the classroom atmosphere, such as playing knowledge-related games related to opera, allowing students to play middle school and consolidate their knowledge. AI technology can make students immersive, make abstract opera culture concrete and influenceable, and invigorate the classroom atmosphere. For example, through AI technology, 360-degree observation of representatives of each profession without blind spots and unique costumes and facial makeup in opera can be felt.

\subsubsection{After class}

Information technology makes after-school homework no longer limited to the paper version. It can consolidate student knowledge in more diverse and rich forms, such as using online teaching platforms to arrange homework and implement targeted guidance for students' interests. Carry out 
personalized guidance and can display homework. In addition to homework, teachers' reflections on the classroom and their understanding of students' knowledge depend on information technology. Through smart classrooms, using artificial intelligence AI classroom observation and analysis systems, they can intelligently observe and record the classroom in all directions and learn about them. Students' classroom behavior performance is analyzed by multiple intelligences, breaking through the traditional teaching model and realizing teaching intelligence.

\section{Conclusion}

To sum up, under the background of information 2.0, information technology can play an influential role in promoting public music courses in secondary vocational schools. From the improvement of equipment, the improvement of teachers' information technology ability to strengthen teachers' awareness of information teaching construction, Promote the development of informatization teaching from all aspects.

\section{References}

[1] Ho, W.-C. (2014). Music education curriculum and social change: a study of popular music in secondary schools in Beijing. China Music Educ. Res. 16, 267-289. doi: 10.1080/14613808.2014.910182

[2] Liu, H., Lin, C.-H., Zhang, D., and Zheng, B. (2018). Chinese language teachers' perceptions of technology and instructional use of technology: a path analysis. J. Educ. Comput. Res. 56, 396-414. doi: 10.1177/0735633117708313

[3] Sun, Z., and Leung, B. W. (2013). A survey of rural primary school music education in Northeastern China. Int. J. Music Educ. 32, 437-461. doi: 10.1177/0255761413491197

[4] Xie, J., and Leung, B. W. (2011). Students' motivation to study music: the mainland China context. Res. Stud. Music Educ. 33, 59-72. doi: 10.1177/1321103X11404654

[5] Yu, Z., and Leung, B. W. (2019). Music teachers and their implementation of the new music curriculum standards in China. Int. J. Music Educ. 37, 178-197. doi: 10.1177/0255761418820647

[6] Yu, D. (2016). Music Education in China 2016. Shanghai: Shanghai Conservatory of Music Press. 